\title{
A Novel Back Tracking based Load Flow Solution for Distribution Systems
}

\author{
R.V.S. Lakshmi Kumari ${ }^{1}$, G. V. Nagesh Kumar², S. Sivanagaraju \\ Department of EEE, Dadi Institute of Engineering and Technology, Visakhapatnam, A.P., India ${ }^{1}$ \\ Department of EEE, Vignan Institute of Information Technology, Visakhapatnam, A.P., India ${ }^{2}$ \\ Department of EEE, University College of Engineering, JNTU Kakinada, Kakinada, A.P., India ${ }^{3}$
}

\begin{abstract}
Power-flow or load-flow studies are very important in determining the overall operation of the existing system as well as for planning of future expansion following the constraints under steady state conditions. Load flow or power flow will give the systematic mathematical approach for obtaining the voltages at the buses, currents through branches and active and reactive power flow through different branches in the given system. In this paper, a new load flow method based on back tracking search algorithm, which in turn uses compensating factors. The system parameters are updated locally and as well as globally to obtain the solution without any iterative processes. The complete methodology is explained with supporting numerical and graphical results for Radial-33 node and Radial-69 node test systems.
\end{abstract}

Keywords: Distribution load flow, Back tracking search algorithm, Local compensating factor, Global compensating factor.

\section{INTRODUCTION}

Distribution load flow algorithms play vital role to estimate system performance under normal and severe conditions. The solution to this problem estimates voltage magnitude, voltage angle at the system nodes, active and reactive power flows in the branches of a given distribution system. The constraints in the load flow problem are in the form of minimum and maximum limits of voltages and reactive powers at the buses in the system.

Usually, static non-linear load flow equations are developed for solving the load flow problem. For this, there are iterative methods such as Gauss Seidel, NR methods are used for solving those equations. But the distribution systems are having high $\mathrm{R} / \mathrm{X}$ ratio compared to the transmission system, due to this reason, the traditional iterative methods mentioned above may provide inaccurate results and may not converge. So many researchers have proposed different load flow methods for both radial and weakly meshed distribution systems.

Fan Zhang and Carol S. Cheng [1] developed modified Newton method for radial distribution systems without decreasing the size of the problem for achieving robust convergence and high efficiency. A. Blengini [2] presented a new open source algorithm based on the object oriented technique to develop load flow solutions in radial distribution systems consisting of all load models. Arturo Losi and Mario Russo [3] presented object oriented load flow based on Newton-Raphson technique by considering some approximations in the Jacobian matrix and derived some convergence conditions. Wei Wu et.al. [4, 5] developed a probabilistic load flow based on the approach using the combination of multiple integral method and cumulate method to reduce the computational burden for achieving satisfactory accuracy. M.H. Haque [6] presented a very simple method of load flow calculation for general distribution system for a meshed network having more than one feeding node.

From the careful review of the literature, it is noticed that, most of the literature is concentrated in finding the solution for the load flow problem using iterative processes. But, in this work, a new methodology based on compensating factors is developed to maximize the solution accuracy and to minimize the computational time by avoiding iterative process. In this process, two compensating factors namely, local compensating factor and global compensating factors are calculated and there by the system parameters are updated. The developed methodology is tested on Radial-33 node and Radial-69 node test systems with supporting numerical and graphical results.

\section{EXISTING DISTRIBUTION LOAD FLOW}

M.H. Haque [1] proposed a general load flow method for distribution systems. To exemplify this, a sample radial distribution system shown in Fig. 1 is considered. Which consists of a branch connected between nodes $\mathrm{k}$ and $\mathrm{m}$, having the resistance $\mathrm{Ri}$ and inductance $\mathrm{Xi}$. Let the loads at node- $\mathrm{k}$ and node- $\mathrm{m}$ are $\left(\mathrm{P}_{\mathrm{L}}^{\mathrm{k}}+\mathrm{j} \mathrm{Q}_{\mathrm{L}}^{\mathrm{k}}\right)$ and $\left(\mathrm{P}_{\mathrm{L}}^{\mathrm{m}}+\mathrm{j} \mathrm{Q}_{\mathrm{L}}^{\mathrm{m}}\right)$ respectively. 
UGC Approved Journal

IJIREEICE

Vol. 5, Issue 7, July 2017

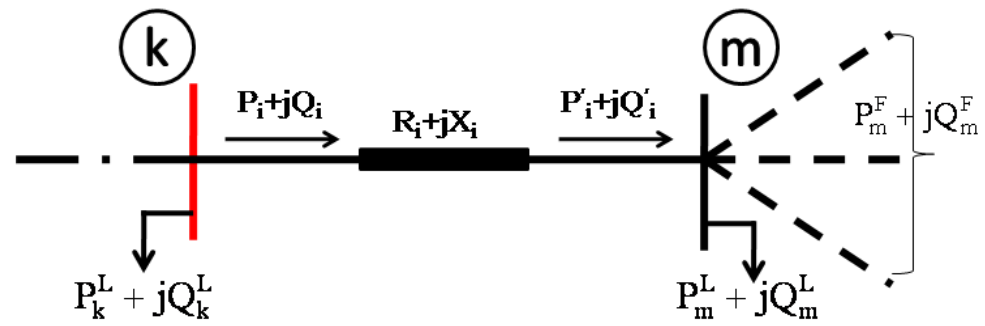

Fig.1 Two node distribution system

The active (Pi) and reactive (Qi) power flow through the branch i near node $\mathrm{k}$ can be written as

$$
\begin{aligned}
& P_{i}=P_{i}^{\prime}+R_{i} \frac{\left(P_{i}^{\prime}\right)^{2}+\left(Q_{i}^{\prime}\right)^{2}}{V_{m}^{2}} \\
& Q_{i}=Q_{i}^{\prime}+X_{i} \frac{\left(P_{i}^{\prime}\right)^{2}+\left(Q_{i}^{\prime}\right)^{2}}{V_{m}^{2}}
\end{aligned}
$$

Where, $\mathrm{P}_{\mathrm{i}}^{\prime}=\mathrm{P}_{\mathrm{m}}^{\mathrm{L}}+\mathrm{P}_{\mathrm{m}}^{\mathrm{F}}$ and $\mathrm{Q}_{\mathrm{i}}^{\prime}=\mathrm{Q}_{\mathrm{m}}^{\mathrm{L}}+\mathrm{Q}_{\mathrm{m}}^{\mathrm{F}}$

The superscripts L, F represents the load, flow respectively. The flow is the sum of power flow through all the downstream branches that are connected to nodee-m. Eqns (1) and (2) can be used in backward direction to find the power flow through all branches in the system.

Once the power flows are known, the voltage magnitude and phase angle at node $\mathrm{m}$ can be calculated from the following equation

$$
\begin{gathered}
\mathrm{V}_{\mathrm{m}}=\sqrt{\mathrm{V}_{\mathrm{k}}^{2}-2\left(\mathrm{P}_{\mathrm{i}}^{1} \mathrm{R}_{\mathrm{i}}+\mathrm{Q}_{\mathrm{i}}^{\prime} \mathrm{X}_{\mathrm{i}}\right)+\left(\left(\mathrm{P}_{\mathrm{i}}^{\prime}\right)^{2}+\left(\mathrm{Q}_{\mathrm{i}}^{\prime}\right)^{2}\right)\left(\mathrm{R}_{\mathrm{i}}^{2}+\mathrm{X}_{\mathrm{i}}^{2}\right) / \mathrm{V}_{\mathrm{k}}^{2}} \\
\delta_{\mathrm{m}}=\delta_{\mathrm{k}}-\tan ^{-1}\left(\frac{\mathrm{a}_{1}}{\mathrm{a}_{2}}\right)
\end{gathered}
$$

Where, $\mathrm{a}_{1}=\frac{\left(\mathrm{P}^{\prime} \mathrm{X}_{\mathrm{i}}-\mathrm{Q}_{\mathrm{i}}^{\prime} \mathrm{R}_{\mathrm{i}}\right)}{\mathrm{V}_{\mathrm{k}}}$ and $\mathrm{a}_{2}=\mathrm{V}_{\mathrm{k}}-\frac{\left(\mathrm{P}^{\prime} \mathrm{X}_{\mathrm{i}}+\mathrm{Q}_{\mathrm{i}}^{\prime} \mathrm{R}_{\mathrm{i}}\right)}{\mathrm{V}_{\mathrm{k}}}$

\section{III.PROPOSED BACK TRACKING LOAD FLOW METHOD}

The proposed methodology starts the process from numbering of nodes and branches and followed by identification of end nodes. At first, for a given distribution system, first node is assumed to be the substation node. The remaining nodes of the main feeder are assigned with the sequential number. The laterals are numbered starting from the substation. The nodes of the lateral are numbered according to the increasing order followed by the main feeder.

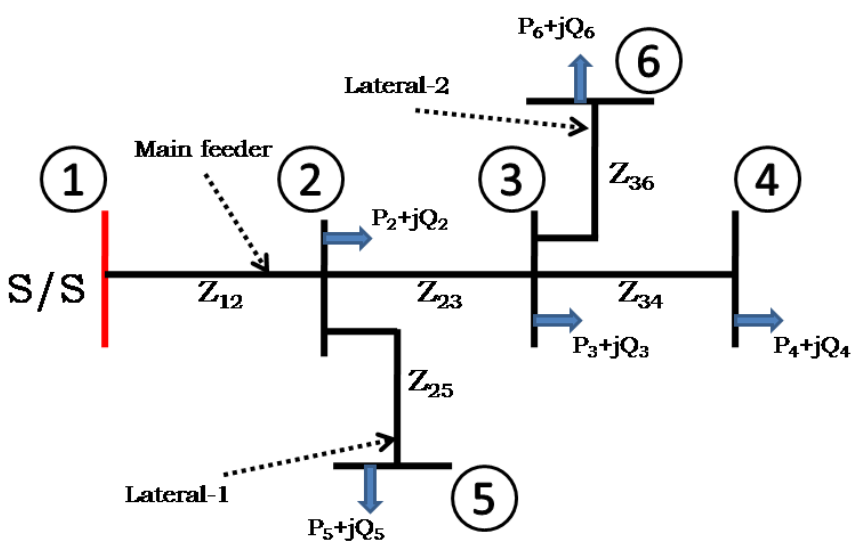

Fig.2 Sample radial distribution system

For example, consider a radial distribution system shown in Fig.2. For this system, the substation node is numbered as node- 1 and the remaining buses of the main feeder are numbered sequentially from node- 2 to node- 4 . The laterals 
UGC Approved Journal

IJIREEICE

Vol. 5, Issue 7, July 2017

connected to main feeder are numbered starting from substation node i.e. lateral connected to node- 2 is lateral- 1 and lateral connected to node- 3 is lateral-2. The nodes of the lateral are numbered in increasing order followed by the main feeder i.e. node connected to later- 1 is numbered as node- 5 and the node connected to lateral- 2 is numbered as node- 6 .

After this process, the end nodes are identified for the main feeder and as well as the laterals by following the highest node number. For example, for the system shown in Fig.2, the end bus for the main feeder is node- 4 , lateral- 1 is node- 5 and for lateral-2 is node- 6 .

Start the next process by assuming flat voltage profile at the end buses $\left(\bar{V}_{n}\right)$ i.e. the voltage at the end nodes to be $1+\mathrm{j} 0$ p.u. Next, current in the braches connected to end node/current at the end nodes (i.e. main feeder/laterals) is calculated as

$$
\overline{\mathrm{I}}_{\mathrm{m}-\mathrm{n}}=\overline{\mathrm{I}}_{\mathrm{n}}=\frac{\mathrm{P}_{\mathrm{n}}-\mathrm{j} \mathrm{Q}_{\mathrm{n}}}{\left(\overline{\mathrm{V}}_{\mathrm{n}}\right)^{*}} ; \mathrm{n}=\text { end nodes }
$$

Where, Pn, Qn are the active and reactive loads connected to nth end node and node- $m$ is the node connected before the end node. For this system, the branch and node current at end nodes $(n=4,5,6)$ is calculated as $\overline{\mathrm{I}}_{3-4}=\overline{\mathrm{I}}_{4}, \overline{\mathrm{I}}_{3-6}=\overline{\mathrm{I}}_{6}$ and $\overline{\mathrm{I}}_{2-5}=\overline{\mathrm{I}}_{5}$.

The voltage magnitude at the mth node i.e. $\overline{\mathrm{V}}_{\mathrm{m}}$ is computed based on the number of branches or/and loads connected to it. This can be expressed as

$$
\overline{\mathrm{V}}_{\mathrm{m}}=\overline{\mathrm{V}}_{\mathrm{n}}+\overline{\mathrm{I}}_{\mathrm{m}-\mathrm{n}} \times \bar{Z}_{\mathrm{m}-\mathrm{n}}
$$

Where, $\bar{Z}_{\mathrm{m}-\mathrm{n}}$ is impedance of the branch connected between nodes $\mathrm{m}$ and $\mathrm{n}$. Here, $\overline{\mathrm{V}}_{\mathrm{n}}$ is assumed to be $(1+\mathrm{j} 0)$ p.u. For the considered system, the voltage at node- 3 is calculated as

From node-4,

$$
\overline{\mathrm{V}}_{3}^{4}=\overline{\mathrm{V}}_{4}+\overline{\mathrm{I}}_{3-4} \times \overline{\mathrm{Z}}_{3-4}
$$

Similarly, from node- $6, \quad \overline{\mathrm{V}}_{3}^{6}=\overline{\mathrm{V}}_{6}+\overline{\mathrm{I}}_{3-6} \times \overline{\mathrm{Z}}_{3-6}$

After calculation of voltage at node-m, the local compensating factor (LCF) for maintaining similar voltage at node-m can be calculated as

$$
\mathrm{LCF}=\frac{\overline{\mathrm{V}}_{\mathrm{m}} \text { (highest value) }}{\overline{\mathrm{V}}_{\mathrm{m}} \text { (lowest value) }}
$$

For the considered system, the LCF is calculated as

$$
\mathrm{LCF}=\frac{\overline{\mathrm{V}}_{3}^{6}}{\overline{\mathrm{V}}_{3}^{4}}\left(\text { by assuming } \overline{\mathrm{V}}_{3}^{6}>\overline{\mathrm{V}}_{3}^{4}\right)
$$

The current in the branch connected to end which yields lowest voltage is updated as

$$
\overline{\mathrm{I}}_{\mathrm{m}-\mathrm{n}}^{\mathrm{new}}=\overline{\mathrm{I}}_{\mathrm{m}-\mathrm{n}}^{\mathrm{old}} \times \mathrm{LCF}
$$

For the considered system, current in the branch connected between nodes 3 and 4 is updated (

$$
\overline{\mathbf{I}}_{3-4}^{\text {new }}=\overline{\mathbf{I}}_{3-4} \text { old } \times \text { LCF }
$$

The above procedure is repeated for all the remaining nodes including substation node. For the considered system, voltage at nodes 2 and 1 is calculated.

In this process, calculated voltage (Vcal) at source node is different from the specified voltage (Vsp). For making unified calculate voltage with the specified voltage, a global compensating factor (GCF) is calculated as

$$
\mathrm{GCF}=\frac{\text { Specified Voltage }\left(\overline{\mathrm{V}}_{\mathrm{sp}}\right)}{\text { Calculated Voltage }\left(\overline{\mathrm{V}}_{\mathrm{cal}}\right)}
$$

Finally, using GCF, the voltage at remaining nodes other than substation node are updated as 
UGC Approved Journal

IJIREEICE

\section{International Journal of Innovative Research in} Electrical, Electronics, Instrumentation and Control Engineering

\section{ISO 3297:2007 Certified}

Vol. 5, Issue 7, July 2017

$$
\overline{\mathrm{V}}_{\mathrm{m}}^{\text {new }}=\overline{\mathrm{V}}_{\mathrm{m}}^{\mathrm{old}} \times \mathrm{GCF}
$$

For the considered system, voltages at the remaining nodes are updated for $m=2,3,4,5$ and 6 . After calculation of new voltages, branch currents are calculated as

$$
\overline{\mathrm{I}}_{\mathrm{m}-\mathrm{n}}=\frac{\left(\overline{\mathrm{V}}_{\mathrm{m}}-\overline{\mathrm{V}}_{\mathrm{n}}\right)}{\mathrm{Z}_{\mathrm{m}-\mathrm{n}}}
$$

Similarly, active and reactive power losses in the branches can be calculated as

$$
\begin{aligned}
& \mathrm{P}_{\mathrm{m}-\mathrm{n}}=\overline{\mathrm{I}}_{\mathrm{m}-\mathrm{n}}^{2} \times \mathrm{R}_{\mathrm{m}-\mathrm{n}} \\
& \mathrm{Q}_{\mathrm{m}-\mathrm{n}}=-\mathrm{I}_{\mathrm{m}-\mathrm{n}}^{2} \times \mathrm{X}_{\mathrm{m}-\mathrm{n}}
\end{aligned}
$$

\section{IV.ALGORITHM FOR LOAD FLOW SOLUTION}

The following algorithm followed to solve load flow problem for both radial and meshed distribution systems.

Step 1: Read distribution system data i.e. line resistance and reactance data, active and reactive load data.

Step 2: Give number to the nodes as per the procedure explained in section-III.

Step 3: Identify end nodes for both the main feeder and laterals.

Step 4: Calculate node voltage using the Eqn (6) and calculate LCF using Eqn (7).

Step 5: Update the line current using Eqn (8).

Step 6: Calculate GCF and updated voltages using Eqns (9) and (10).

Step 7: Calculate line current and there by the losses using Eqns (11) to (13).

\section{RESULTS AND ANALYSIS}

To demonstrate the effectiveness of the proposed load flow methodology over the existing load flow methodology, two test systems namely Radial-33 node and Radial-69 are considered [7, 8].

The entire analysis is performed for the following four cases.

Case-1: Load flow problem is solved for the radial-33 and distribution system using the existing and proposed methodologies (explained in sections II and III).

Case-2: Load flow problem is solved for the radial- 69 node distribution system using the existing and proposed methodologies (explained in sections II and III).

\section{A. Case-1}

In this case, Radial-33 node distribution system with 32 branches, $3715 \mathrm{~kW}$ active load and $2300 \mathrm{kVAr}$ reactive load is considered.

In case 1, the load flow problem is solved using existing and proposed load flow methodologies and obtained results are tabulated in Table.1. From this table, it is observed that, the voltage profile of the proposed methodology is very slightly higher when compared to the existing methodology. This is because of the updating system parameters locally and as well as globally without considering any simplifications. The variation of voltage magnitude is shown in Fig.5.

TABLE.1 LOAD FLOW RESULTS FOR CASE-1

\begin{tabular}{|c|c|c|c|c|}
\hline \multirow{2}{*}{$\begin{array}{c}\text { Node } \\
\text { No }\end{array}$} & \multicolumn{2}{|c|}{ Existing method [8] } & \multicolumn{2}{c|}{ Proposed Method } \\
\cline { 2 - 5 } & Voltage Magnitude (p.u.) & Voltage Angle (deg) & Voltage Magnitude (p.u.) & Voltage Angle (deg) \\
\hline 1 & 1 & 0 & 1.0000 & 0.0000 \\
\hline 2 & 0.997 & 0.0148 & 0.9974 & 0.0124 \\
\hline 3 & 0.983 & 0.0985 & 0.9851 & 0.0846 \\
\hline 4 & 0.9755 & 0.1658 & 0.9787 & 0.1424 \\
\hline 5 & 0.9682 & 0.2341 & 0.9724 & 0.2006 \\
\hline 6 & 0.9498 & 0.1446 & 0.9568 & 0.1249 \\
\hline 7 & 0.9463 & -0.0872 & 0.9538 & -0.0676 \\
\hline 8 & 0.9415 & -0.0539 & 0.9497 & -0.0358 \\
\hline 9 & 0.9352 & -0.1312 & 0.9444 & -0.0956 \\
\hline
\end{tabular}


UGC Approved Journal

IJIREEICE

International Journal of Innovative Research in Electrical, Electronics, Instrumentation and Control Engineering

ISO 3297:2007 Certified

Vol. 5, Issue 7, July 2017

\begin{tabular}{|l|c|c|c|c|}
\hline 10 & 0.9294 & -0.198 & 0.9395 & -0.1468 \\
\hline 11 & 0.9286 & -0.1914 & 0.9387 & -0.1406 \\
\hline 12 & 0.9271 & -0.1812 & 0.9375 & -0.1307 \\
\hline 13 & 0.921 & -0.2778 & 0.9323 & -0.2063 \\
\hline 14 & 0.9187 & -0.3585 & 0.9304 & -0.2717 \\
\hline 15 & 0.9173 & -0.3976 & 0.9292 & -0.3031 \\
\hline 16 & 0.916 & -0.4223 & 0.9280 & -0.3225 \\
\hline 17 & 0.914 & -0.5017 & 0.9263 & -0.3869 \\
\hline 18 & 0.9134 & -0.512 & 0.9258 & -0.3949 \\
\hline 19 & 0.9479 & 0.0039 & 0.9969 & 0.0018 \\
\hline 20 & 0.9453 & -0.0636 & 0.9933 & -0.0639 \\
\hline 21 & 0.9339 & -0.0831 & 0.9927 & -0.0830 \\
\hline 22 & 0.9257 & -0.1036 & 0.9920 & -0.1030 \\
\hline 23 & 0.9222 & 0.0673 & 0.9817 & 0.0557 \\
\hline 24 & 0.918 & -0.022 & 0.9754 & -0.0275 \\
\hline 25 & 0.9171 & -0.0662 & 0.9723 & -0.0686 \\
\hline 26 & 0.9168 & 0.1858 & 0.9551 & 0.1584 \\
\hline 27 & 0.9794 & 0.2443 & 0.9530 & 0.2061 \\
\hline 28 & 0.9727 & 0.3386 & 0.9432 & 0.2774 \\
\hline 29 & 0.9694 & 0.4249 & 0.9362 & 0.3439 \\
\hline 30 & 0.9965 & 0.5338 & 0.9332 & 0.4329 \\
\hline 31 & 0.9929 & 0.4534 & 0.9297 & 0.3620 \\
\hline 32 & 0.9922 & 0.4312 & 0.9289 & 0.3426 \\
\hline 33 & 0.9916 & 0.4237 & 0.9286 & 0.3362 \\
\hline
\end{tabular}

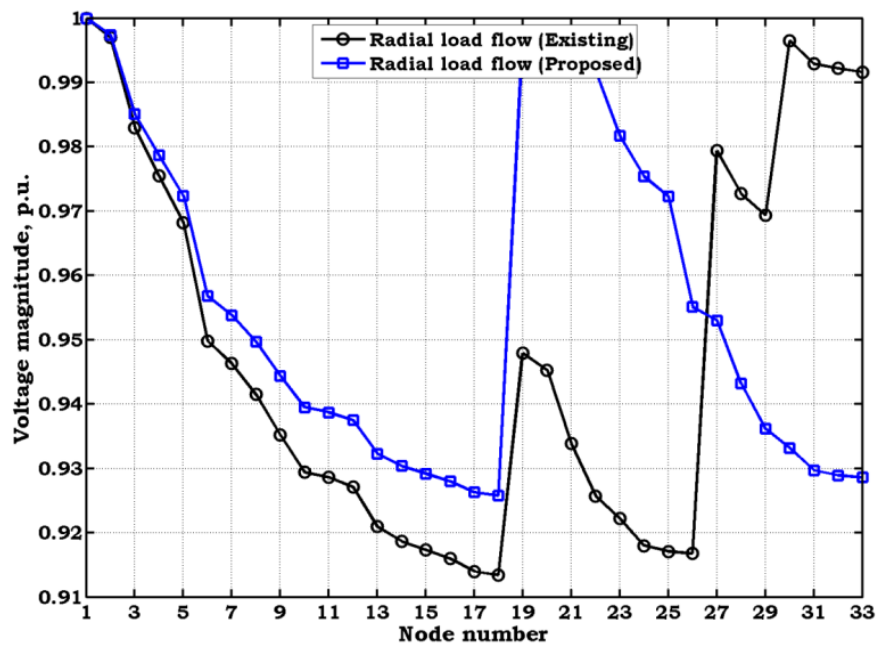

Fig.5 Variation of Voltage Magnitude for case 1

Similarly, the active and reactive power losses in each of the branch for the existing and proposed load flow methodologies are tabulated in Table. 2 and the respective variation is shown in Fig.6

TABLE.2 POWER LOSSES FOR CASE 1

\begin{tabular}{|c|c|c|c|c|c|c|}
\hline \multirow{2}{*}{ Branch No } & \multirow{2}{*}{ Sending Node } & \multirow{2}{*}{ Receiving Node } & \multicolumn{2}{|c|}{ Existing method [8] } & \multicolumn{2}{c|}{ Proposed method } \\
\cline { 4 - 7 } & & & Ploss (kW) & Qloss (kVAr) & Ploss (kW) & Qloss (kVAr) \\
\hline 1 & 1 & 2 & 12.1927 & 6.2154 & 12.0168 & 6.1257 \\
\hline 2 & 2 & 3 & 51.5711 & 26.2668 & 50.7392 & 25.8430 \\
\hline 3 & 3 & 4 & 19.7934 & 10.0806 & 19.3907 & 9.8755 \\
\hline 4 & 4 & 5 & 18.5931 & 9.4697 & 18.2012 & 9.2702 \\
\hline 5 & 5 & 6 & 38.0256 & 32.8256 & 37.2126 & 32.1237 \\
\hline
\end{tabular}


UGC Approved Journal

IJIREEICE

International Journal of Innovative Research in Electrical, Electronics, Instrumentation and Control Engineering

ISO 3297:2007 Certified

Vol. 5, Issue 7, July 2017

\begin{tabular}{|c|c|c|c|c|c|c|}
\hline 6 & 6 & 7 & 1.9131 & 6.3238 & 1.8726 & 6.1900 \\
\hline 7 & 7 & 8 & 4.8342 & 1.5976 & 4.7257 & 1.5617 \\
\hline 8 & 8 & 9 & 4.1773 & 3.0012 & 4.0771 & 2.9292 \\
\hline 9 & 9 & 10 & 3.5575 & 2.5216 & 3.4707 & 2.4601 \\
\hline 10 & 10 & 11 & 0.5531 & 0.1829 & 0.5394 & 0.1783 \\
\hline 11 & 11 & 12 & 0.8802 & 0.2911 & 0.8582 & 0.2838 \\
\hline 12 & 12 & 13 & 2.6638 & 2.0958 & 2.5960 & 2.0425 \\
\hline 13 & 13 & 14 & 0.7286 & 0.9590 & 0.7098 & 0.9344 \\
\hline 14 & 14 & 15 & 0.3569 & 0.3176 & 0.3475 & 0.3093 \\
\hline 15 & 15 & 16 & 0.2813 & 0.2054 & 0.2739 & 0.2000 \\
\hline 16 & 16 & 17 & 0.2515 & 0.3358 & 0.2448 & 0.3268 \\
\hline 17 & 17 & 18 & 0.0531 & 0.0416 & 0.0517 & 0.0405 \\
\hline 18 & 2 & 19 & 0.1610 & 0.1536 & 0.1608 & 0.1535 \\
\hline 19 & 19 & 20 & 0.8322 & 0.7498 & 0.8315 & 0.7492 \\
\hline 20 & 20 & 21 & 0.1008 & 0.1177 & 0.1007 & 0.1176 \\
\hline 21 & 21 & 22 & 0.0436 & 0.0577 & 0.0436 & 0.0576 \\
\hline 22 & 3 & 23 & 3.1812 & 2.1737 & 3.1635 & 2.1616 \\
\hline 23 & 23 & 24 & 5.1432 & 4.0613 & 5.1140 & 4.0382 \\
\hline 24 & 24 & 25 & 1.2873 & 1.0073 & 1.2798 & 1.0014 \\
\hline 25 & 6 & 26 & 2.5940 & 1.3213 & 2.5348 & 1.2911 \\
\hline 26 & 26 & 27 & 3.3211 & 1.6909 & 3.2440 & 1.6517 \\
\hline 27 & 27 & 28 & 11.2766 & 9.9424 & 11.0105 & 9.7078 \\
\hline 28 & 28 & 29 & 7.8180 & 6.8108 & 7.6318 & 6.6487 \\
\hline 29 & 29 & 30 & 3.8881 & 1.9805 & 3.7948 & 1.9329 \\
\hline 30 & 30 & 31 & 1.5928 & 1.5742 & 1.5529 & 1.5347 \\
\hline 31 & 31 & 32 & 0.2131 & 0.2484 & 0.2077 & 0.2421 \\
\hline 32 & 32 & 33 & 0.0132 & 0.0205 & 0.0128 & 0.0199 \\
\hline \multicolumn{2}{|r|}{ Total Power Loss (KW) } & 201.8925 & 134.6413 & 198.011 & 132.002 \\
\hline
\end{tabular}

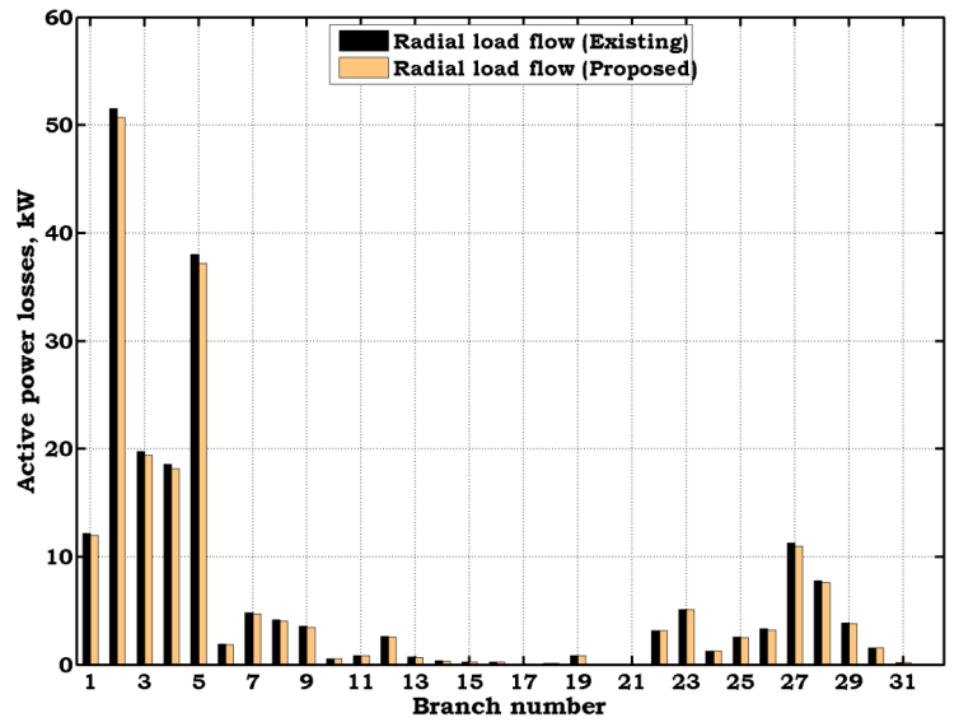

Fig.6 Variation of active power losses for case 1

Similarly, the consolidated results for this case are tabulated in Table.3. From this table, it is identified that, due to effectiveness of the proposed load flow methodology, the total active power losses are decreased when compared to the existing load flow methodology. Similarly, with the proposed method, the low voltage node is identified to be 18 , which is farer from the source node. It is also observed that, due to reduced complexity of mathematics and minimized number of mathematical computations in the proposed method, computational time taken is reduced drastically when compared to existing load flow method. 
UGC Approved Journal

IJIREEICE

International Journal of Innovative Research in Electrical, Electronics, Instrumentation and Control Engineering

ISO 3297:2007 Certified

Vol. 5, Issue 7, July 2017

TABLE. 3 CONSOLIDATED LOAD FLOW RESULTS FOR CASE 1

\begin{tabular}{|l|c|c|}
\hline \multicolumn{1}{|c|}{ Parameter } & Existing radial load flow method [8] & Proposed load flow method \\
\hline Total active power losses (kW) & 201.8925 & 198.011 \\
\hline Total reactive power losses (kVAr) & 134.6413 & 132.002 \\
\hline Minimum voltage node & 18 & 18 \\
\hline Minimum voltage (p.u) & 0.9134 & 0.9258 \\
\hline Computational time (sec) & 0.17 & 0.06 \\
\hline
\end{tabular}

B. Case-2

In this example, Radial -69 node distribution system with 68 branches, $3802 \mathrm{~kW}$ active load and $2695 \mathrm{kVAr}$ reactive load is considered.

In case 2, the load flow problem is solved using existing and proposed load flow methodologies and obtained results are tabulated in Table.4. From this table, it is observed that, the voltage profile of the proposed methodology is very slightly higher when compared to the existing methodology. This is because of the updating system parameters locally and as well as globally without considering any simplifications. The variation of voltage magnitude is shown in Fig. 7.

TABLE.4 LOAD FLOW RESULTS FOR CASE 2

\begin{tabular}{|c|c|c|c|c|}
\hline \multirow{2}{*}{$\begin{array}{c}\text { Node } \\
\text { No }\end{array}$} & \multicolumn{2}{|c|}{ Existing method [8] } & \multicolumn{2}{c|}{ Proposed Method } \\
\hline 1 & 1 & 0 & 1.0000 & Voltage Angle (deg) \\
\hline 2 & 1 & -0.0012 & 1.0000 & 0.0000 \\
\hline 3 & 0.9999 & -0.0024 & 0.9999 & -0.0011 \\
\hline 4 & 0.9998 & -0.0057 & 0.9999 & -0.0022 \\
\hline 5 & 0.999 & -0.0168 & 0.9991 & -0.0163 \\
\hline 6 & 0.9901 & 0.0672 & 0.9914 & 0.0417 \\
\hline 7 & 0.9809 & 0.156 & 0.9834 & 0.1028 \\
\hline 8 & 0.9787 & 0.1774 & 0.9815 & 0.1175 \\
\hline 9 & 0.9776 & 0.1885 & 0.9805 & 0.1251 \\
\hline 10 & 0.9726 & 0.2775 & 0.9759 & 0.2022 \\
\hline 11 & 0.9715 & 0.2973 & 0.9748 & 0.2193 \\
\hline 12 & 0.9683 & 0.3531 & 0.9336 & 0.7822 \\
\hline 13 & 0.9654 & 0.4028 & 0.9310 & 0.8247 \\
\hline 14 & 0.9625 & 0.4528 & 0.9285 & 0.8675 \\
\hline 15 & 0.9597 & 0.5019 & 0.9259 & 0.9094 \\
\hline 16 & 0.9592 & 0.5111 & 0.9255 & 0.9173 \\
\hline 17 & 0.9583 & 0.5262 & 0.9247 & 0.9302 \\
\hline 18 & 0.9583 & 0.5264 & 0.9247 & 0.9303 \\
\hline 19 & 0.9578 & 0.5354 & 0.9243 & 0.9381 \\
\hline 20 & 0.9575 & 0.5413 & 0.9240 & 0.9432 \\
\hline 21 & 0.957 & 0.5507 & 0.9236 & 0.9513 \\
\hline 22 & 0.957 & 0.5509 & 0.9236 & 0.9514 \\
\hline 23 & 0.957 & 0.5523 & 0.9235 & 0.9526 \\
\hline 24 & 0.9568 & 0.5554 & 0.9234 & 0.9553 \\
\hline 25 & 0.9566 & 0.5587 & 0.9232 & 0.9581 \\
\hline 26 & 0.9566 & 0.5601 & 0.9232 & 0.9593 \\
\hline 27 & 0.9566 & 0.5605 & 0.9232 & 0.9597 \\
\hline 28 & 0.9999 & -0.0026 & 0.9999 & -0.0025 \\
\hline 29 & 0.9999 & -0.0052 & 0.9999 & -0.0051 \\
\hline 30 & 0.9997 & -0.0031 & 0.9997 & -0.0029 \\
\hline 31 & 0.9997 & -0.0027 & 0.9997 & -0.0026 \\
\hline 32 & 0.9996 & -0.0008 & 0.9996 & -0.0007 \\
\hline 33 & 0.9993 & 0.0036 & 0.9994 & 0.0037 \\
\hline 34 & 0.999 & 0.0094 & 0.9990 & 0.0096 \\
\hline & & & & \\
\hline & & & & Voltage Magnitude (p.u.) \\
\hline
\end{tabular}


UGC Approved Journal

IJIREEICE

International Journal of Innovative Research in Electrical, Electronics, Instrumentation and Control Engineering

ISO 3297:2007 Certified

Vol. 5, Issue 7, July 2017

\begin{tabular}{|l|l|l|l|l|}
\hline 35 & 0.9989 & 0.0105 & 0.9990 & 0.0106 \\
\hline 36 & 0.9999 & -0.0029 & 0.9999 & -0.0027 \\
\hline 37 & 0.9997 & -0.0093 & 0.9998 & -0.0091 \\
\hline 38 & 0.9996 & -0.0117 & 0.9996 & -0.0115 \\
\hline 39 & 0.9995 & -0.0124 & 0.9996 & -0.0122 \\
\hline 40 & 0.9995 & -0.0125 & 0.9995 & -0.0122 \\
\hline 41 & 0.9988 & -0.0235 & 0.9989 & -0.0232 \\
\hline 42 & 0.9986 & -0.0282 & 0.9986 & -0.0278 \\
\hline 43 & 0.9985 & -0.0288 & 0.9985 & -0.0284 \\
\hline 44 & 0.9985 & -0.0289 & 0.9985 & -0.0286 \\
\hline 45 & 0.9984 & -0.0307 & 0.9984 & -0.0304 \\
\hline 46 & 0.9984 & -0.0307 & 0.9984 & -0.0304 \\
\hline 47 & 0.9998 & -0.0075 & 0.9998 & -0.0071 \\
\hline 48 & 0.9985 & -0.0528 & 0.9986 & -0.0513 \\
\hline 49 & 0.9947 & -0.1935 & 0.9948 & -0.1887 \\
\hline 50 & 0.9942 & -0.2135 & 0.9942 & -0.2083 \\
\hline 51 & 0.9786 & 0.1777 & 0.9814 & 0.1178 \\
\hline 52 & 0.9786 & 0.1779 & 0.9814 & 0.1180 \\
\hline 53 & 0.9748 & 0.2173 & 0.9781 & 0.1435 \\
\hline 54 & 0.9716 & 0.2509 & 0.9754 & 0.1651 \\
\hline 55 & 0.9671 & 0.2979 & 0.9717 & 0.1951 \\
\hline 56 & 0.9628 & 0.3441 & 0.9680 & 0.2247 \\
\hline 57 & 0.9407 & 0.7998 & 0.9491 & 0.5562 \\
\hline 58 & 0.9298 & 1.0324 & 0.9398 & 0.7246 \\
\hline 59 & 0.9256 & 1.1252 & 0.9362 & 0.7917 \\
\hline 60 & 0.9206 & 1.2438 & 0.9320 & 0.8782 \\
\hline 61 & 0.9133 & 1.3341 & 0.9258 & 0.9352 \\
\hline 62 & 0.913 & 1.3377 & 0.9256 & 0.9374 \\
\hline 63 & 0.9126 & 1.3425 & 0.9252 & 0.9405 \\
\hline 64 & 0.9107 & 1.366 & 0.9236 & 0.9552 \\
\hline 65 & 0.9102 & 1.3731 & 0.9232 & 0.9597 \\
\hline 66 & 0.9714 & 0.2984 & 0.9364 & 0.7351 \\
\hline 67 & 0.9714 & 0.2985 & 0.9364 & 0.7351 \\
\hline 68 & 0.968 & 0.3594 & 0.9333 & 0.7879 \\
\hline 69 & 0.968 & 0.3594 & 0.9333 & \\
\hline & & & & \\
\hline & & & & \\
\hline & & & & \\
\hline & & & & \\
\hline
\end{tabular}

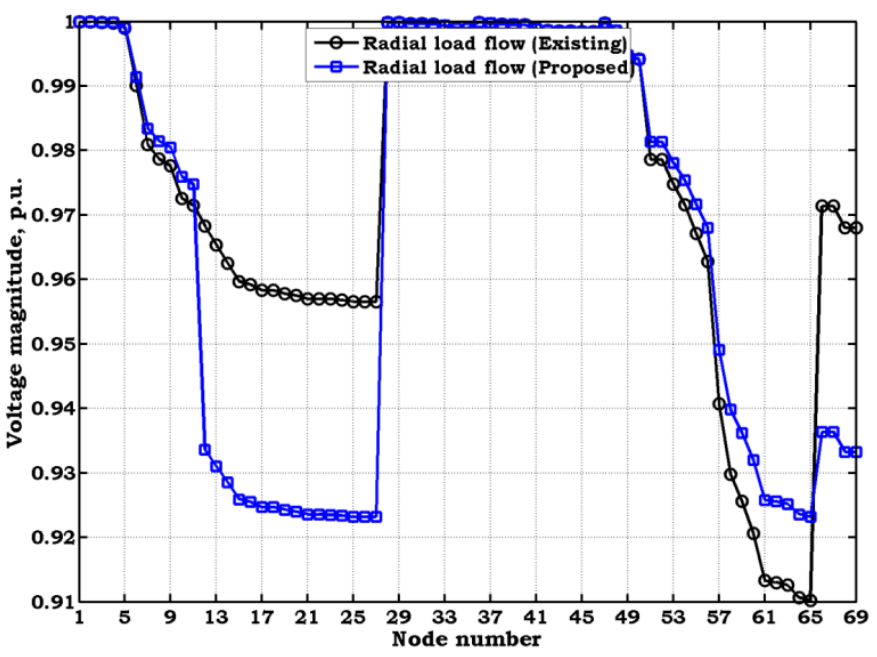

Fig.7 Variation of Voltage Magnitude for case 2

Similarly, the active and reactive power losses in each of the branch for the existing and proposed load flow methodologies are tabulated in Table.5 and the respective variation is shown in Fig. 8 
UGC Approved Journal

IJIREEICE

International Journal of Innovative Research in Electrical, Electronics, Instrumentation and Control Engineering

ISO 3297:2007 Certified

Vol. 5, Issue 7, July 2017

TABLE. 5 POWER LOSSES FOR CASE 2

\begin{tabular}{|c|c|c|c|c|c|c|}
\hline \multirow{2}{*}{$\begin{array}{c}\text { Branch } \\
\text { No }\end{array}$} & \multirow{2}{*}{$\begin{array}{c}\text { Sending } \\
\text { Node }\end{array}$} & \multirow{2}{*}{$\begin{array}{l}\text { Receiving } \\
\text { Node }\end{array}$} & \multicolumn{2}{|c|}{ Existing method [8] } & \multicolumn{2}{|c|}{ Proposed Method } \\
\hline & & & Ploss (kW) & Qloss (kVAr) & Ploss $(\mathbf{k W})$ & Qloss (kVAr) \\
\hline 1 & 1 & 2 & 0.0749 & 0.1798 & 0.0748 & 0.1795 \\
\hline 2 & 2 & 3 & 0.0749 & 0.1798 & 0.0748 & 0.1795 \\
\hline 3 & 3 & 4 & 0.1947 & 0.4674 & 0.1944 & 0.4665 \\
\hline 4 & 4 & 5 & 1.9339 & 2.2653 & 1.9294 & 2.2599 \\
\hline 5 & 5 & 6 & 28.2001 & 14.362 & 28.1338 & 14.3283 \\
\hline 6 & 6 & 7 & 29.2986 & 14.9261 & 29.2297 & 14.8910 \\
\hline 7 & 7 & 8 & 6.8844 & 3.5094 & 6.8685 & 3.5013 \\
\hline 8 & 8 & 9 & 3.3698 & 1.7157 & 3.3626 & 1.7120 \\
\hline 9 & 9 & 10 & 4.7772 & 1.579 & 5.0447 & 1.6674 \\
\hline 10 & 10 & 11 & 1.0148 & 0.3355 & 1.0740 & 0.3551 \\
\hline 11 & 11 & 12 & 2.1920 & 0.7244 & 2.3555 & 0.7784 \\
\hline 12 & 12 & 13 & 1.2868 & 0.4248 & 1.3819 & 0.4562 \\
\hline 13 & 13 & 14 & 1.2464 & 0.4059 & 1.3384 & 0.4359 \\
\hline 14 & 14 & 15 & 1.2055 & 0.3983 & 1.2946 & 0.4278 \\
\hline 15 & 15 & 16 & 0.2240 & 0.0741 & 0.2406 & 0.0795 \\
\hline 16 & 16 & 17 & 0.3207 & 0.106 & 0.3444 & 0.1139 \\
\hline 17 & 17 & 18 & 0.0026 & 0.0009 & 0.0028 & 0.0010 \\
\hline 18 & 18 & 19 & 0.1043 & 0.0345 & 0.1120 & 0.0370 \\
\hline 19 & 19 & 20 & 0.0671 & 0.022 & 0.0720 & 0.0236 \\
\hline 20 & 20 & 21 & 0.1076 & 0.0356 & 0.1155 & 0.0382 \\
\hline 21 & 21 & 22 & 0.0005 & 0.0002 & 0.0006 & 0.0002 \\
\hline 22 & 22 & 23 & 0.0051 & 0.0017 & 0.0055 & 0.0018 \\
\hline 23 & 23 & 24 & 0.0112 & 0.0037 & 0.0120 & 0.0040 \\
\hline 24 & 24 & 25 & 0.0060 & 0.002 & 0.0065 & 0.0021 \\
\hline 25 & 25 & 26 & 0.0025 & 0.0008 & 0.0027 & 0.0009 \\
\hline 26 & 26 & 27 & 0.0003 & 0.0001 & 0.0004 & 0.0001 \\
\hline 27 & 3 & 28 & 0.0003 & 0.0009 & 0.0003 & 0.0009 \\
\hline 28 & 28 & 29 & 0.0026 & 0.0063 & 0.0026 & 0.0063 \\
\hline 29 & 29 & 30 & 0.0058 & 0.0019 & 0.0058 & 0.0019 \\
\hline 30 & 30 & 31 & 0.0010 & 0.0003 & 0.0010 & 0.0003 \\
\hline 31 & 31 & 32 & 0.0051 & 0.0017 & 0.0051 & 0.0017 \\
\hline 32 & 32 & 33 & 0.0123 & 0.0041 & 0.0123 & 0.0041 \\
\hline 33 & 33 & 34 & 0.0104 & 0.0034 & 0.0104 & 0.0034 \\
\hline 34 & 34 & 35 & 0.0005 & 0.0002 & 0.0005 & 0.0002 \\
\hline 35 & 3 & 36 & 0.0014 & 0.0034 & 0.0014 & 0.0034 \\
\hline 36 & 36 & 37 & 0.0151 & 0.0369 & 0.0151 & 0.0369 \\
\hline 37 & 37 & 38 & 0.0173 & 0.0202 & 0.0173 & 0.0202 \\
\hline 38 & 38 & 39 & 0.0050 & 0.0058 & 0.0050 & 0.0058 \\
\hline 39 & 39 & 40 & 0.0002 & 0.0002 & 0.0002 & 0.0002 \\
\hline 40 & 40 & 41 & 0.0487 & 0.0569 & 0.0487 & 0.0569 \\
\hline 41 & 41 & 42 & 0.0201 & 0.0235 & 0.0201 & 0.0235 \\
\hline 42 & 42 & 43 & 0.0027 & 0.0031 & 0.0027 & 0.0031 \\
\hline 43 & 43 & 44 & 0.0005 & 0.0006 & 0.0005 & 0.0006 \\
\hline 44 & 44 & 45 & 0.0061 & 0.0077 & 0.0061 & 0.0077 \\
\hline 45 & 45 & 46 & 0.0000 & 0 & 0.0000 & 0.0000 \\
\hline 46 & 4 & 47 & 0.0233 & 0.0575 & 0.0233 & 0.0575 \\
\hline 47 & 47 & 48 & 0.5828 & 1.4265 & 0.5827 & 1.4263 \\
\hline 48 & 48 & 49 & 1.6334 & 3.9968 & 1.6333 & 3.9963 \\
\hline 49 & 49 & 50 & 0.1159 & 0.2835 & 0.1159 & 0.2835 \\
\hline 50 & 8 & 51 & 0.0018 & 0.0009 & 0.0017 & 0.0009 \\
\hline 51 & 51 & 52 & 0.0000 & 0 & 0.0000 & 0.0000 \\
\hline
\end{tabular}


UGC Approved Journal

IJIREEICE

International Journal of Innovative Research in Electrical, Electronics, Instrumentation and Control Engineering

ISO 3297:2007 Certified

Vol. 5, Issue 7, July 2017

\begin{tabular}{|c|c|c|c|c|c|c|}
\hline 52 & 52 & 53 & 5.7696 & 2.9378 & 5.6185 & 2.8609 \\
\hline 53 & 53 & 54 & 6.6978 & 3.4116 & 6.5221 & 3.3221 \\
\hline 54 & 54 & 55 & 9.1059 & 4.6362 & 8.8645 & 4.5134 \\
\hline 55 & 55 & 56 & 8.7718 & 4.4685 & 8.5372 & 4.3490 \\
\hline 56 & 56 & 57 & 49.5809 & 16.6423 & 48.2550 & 16.1973 \\
\hline 57 & 57 & 58 & 24.4381 & 8.2011 & 23.7846 & 7.9818 \\
\hline 58 & 58 & 59 & 9.4859 & 3.137 & 9.2322 & 3.0531 \\
\hline 59 & 59 & 60 & 10.6485 & 3.2323 & 10.3610 & 3.1451 \\
\hline 60 & 60 & 61 & 13.9966 & 7.1293 & 13.6187 & 6.9368 \\
\hline 61 & 61 & 62 & 0.1118 & 0.0569 & 0.1087 & 0.0554 \\
\hline 62 & 62 & 63 & 0.1346 & 0.0685 & 0.1309 & 0.0666 \\
\hline 63 & 63 & 64 & 0.6597 & 0.336 & 0.6414 & 0.3267 \\
\hline 64 & 64 & 65 & 0.0411 & 0.0209 & 0.0400 & 0.0204 \\
\hline 65 & 11 & 66 & 0.0026 & 0.0008 & 0.0028 & 0.0009 \\
\hline 66 & 66 & 67 & 0.0000 & 0 & 0.0000 & 0.0000 \\
\hline 67 & 12 & 68 & 0.0233 & 0.0077 & 0.0251 & 0.0083 \\
\hline 68 & 68 & 69 & 0.0000 & 0 & 0.0000 & 0.0000 \\
\hline \multicolumn{3}{|c|}{ Total Power Loss (KW) } & 224.5867 & 101.9848 & 221.526 & 100.720 \\
\hline
\end{tabular}

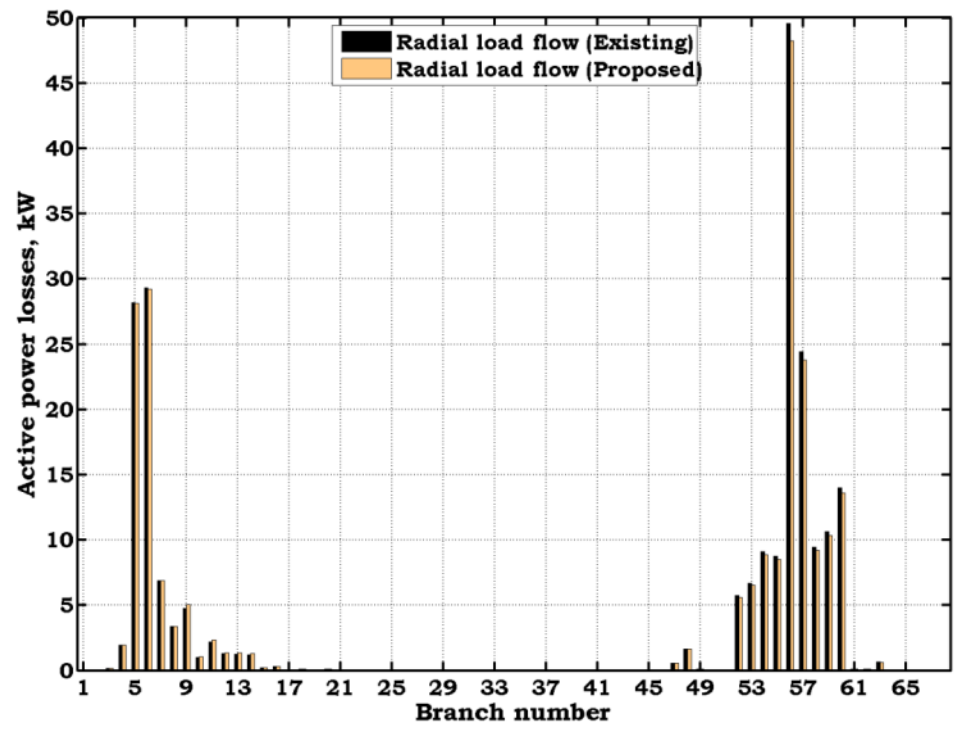

Fig. 8 Variation of active power losses for case 2

Similarly, the consolidated results for this case are tabulated in Table.6. From this table, it is identified that, due to effectiveness of the proposed load flow methodology, the total active power losses are decreased when compared to the existing load flow methodology. Similarly, with the proposed method, the low voltage node is identified to be 65 , which is farer from the source node. It is also observed that, due to reduced complexity of mathematics and minimized number of mathematical computations in the proposed method, computational time taken is reduced drastically when compared to existing load flow method.

TABLE.6 CONSOLIDATED LOAD FLOW RESULTS FOR CASE 2

\begin{tabular}{|l|c|c|}
\hline \multicolumn{1}{|c|}{ Parameter } & Existing radial load flow method [8] & Proposed load flow method \\
\hline Total active power losses $(\mathrm{kW})$ & 224.5867 & 221.526 \\
\hline Total reactive power losses $(\mathrm{kVAr})$ & 101.9848 & 100.720 \\
\hline Minimum voltage node & 0.9102 & 0.9232 \\
\hline Minimum voltage (p.u) & 65 & 65 \\
\hline Computational time $(\mathrm{sec})$ & 0.27 & 0.12 \\
\hline
\end{tabular}


UGC Approved Journal

IJIREEICE

Vol. 5, Issue 7, July 2017

\section{VI.CONCLUSIONS}

In this paper, a new methodology to solve load flow problem has been presented with necessary mathematical derivations. The back tracking radial load flow method has been used to solve load flow problem for radial distribution systems. From the analysis, it has been summarized that, updating system variables locally and as well as globally, the proposed methodology yields better results when compared to existing methodologies. The entire methodology has been tested on Radial-33 node and Radial-69 node test systems with supporting numerical and graphical results.

\section{REFERENCES}

[1] Fan Zhang, Carol S. Cheng, "A Modified Newton Method for Radial Distribution System Power Flow Analysis”, IEEE Transaction on Power Delivery, 1997, Vol. 12, No 1, pp.389-397.

[2] A. Blengini, M. F. H. Carvalho, L. T. M. Mota, C. C. Pezzuto, “Object-Oriented Load Flow Modeling And Implementation For Distribution Power System", IEEE Latin America Transactions, 2017, Vol. 15, No 3, pp.439-444.

[3] A. Arturo Losi, Mario Russo, "Object-Oriented Load Flow for Radial and Weakly Meshed Distribution Networks", IEEE Transactions on Power Systems, 2003, Vol. 18, No 4, pp.1265 -1274.

[4] A Wei Wu, Keyou Wang, Guojie Li, Xiuchen Jiang, Zhiming Wang, "Probabilistic load flow calculation using cumulants and multiple integrals", IET Generation, Transmission \& Distribution, 2016, Vol. 10, Issue 7, pp. 1703-1709.

[5] Hamed Ahmadi, Member, José R. Marti, Alexan dra von Meier, "A Linear Power Flow Formulation for Three-Phase Distribution Systems", IEEE Transactions on Power Systems, DOI: 10.1109/TPWRS.2016.2533540.

[6] M.H. Haque, "A general load flow method for distribution systems", Electric Power Systems Research, 2000, Vol.54, pp.47-54.

[7] Paulo A. N. Garcia, Jose Luiz R. Pereira, Sandoval Carneiro, Vander M. da Costa, Nelson Martins, "Three-Phase Power Flow Calculations Using the Current Injection Method", IEEE Transactions on Power Systems, 2000, Vol. 15, No 2, pp.508-514.

[8] G. W. Chang, S. Y. Chu, H. L. Wang, "An Improved Backward/Forward Sweep Load Flow Algorithm for Radial Distribution Systems", IEEE Transactions on Power Systems, 2007, Vol. 22, No 2, pp.882-884. 